\title{
An Experimental Investigation on Slamming Kinematics, Impulse and Energy Transfer for High-Speed Catamarans Equipped with Ride Control Systems
}

\author{
Javad AlaviMehr ${ }^{1, *}$, Jason Lavroff ${ }^{2}$, Michael R. Davis ${ }^{2}$, Damien S. Holloway ${ }^{2}$, Giles A.Thomas ${ }^{3}$ \\ ${ }^{1}$ NCMEH, AMC, University of Tasmania, Locked Bag 1395, Launceston TAS 7250, Australia \\ ${ }^{2}$ School of Engineering, AMC, University of Tasmania, Australia \\ ${ }^{3}$ Department of Mechanical Engineering, University College London, England, United Kingdom \\ *Corresponding author. Email address: Javad.Alavimehr@utas.edu.au
}

\begin{abstract}
The operation of high-speed craft in large waves can produce significant vessel motions that lead to passenger discomfort and extreme loadings sustained by the hull structure during full bow immersion and wave slam impact. These large motions and loads can be significantly reduced by a Ride Control System (RCS). The influence of ride control algorithms on the motion and load response of a $112 \mathrm{~m}$ high-speed wave-piercing catamaran was previously investigated by the authors using a $2.5 \mathrm{~m}$ hydroelastic segmented model fitted with a ride control system. The present study extends this to investigate the influence of the control algorithms on the slamming kinematics, water entry impulse and energy transfer. The model ride control system comprised two transom stern tabs and a central T-Foil beneath the bow. In order to activate the model scale ride control system and surfaces in a closed loop system six ideal motion control feedback algorithms were developed: local motion, heave and pitch control, each in a linear and nonlinear application. These results were compared with the results with inactive but present control surfaces and with no control surfaces fitted. From these analyses it was found that the pitch control mode was most effective where in $60 \mathrm{~mm}$ model scale waves it significantly reduced the water entry impulse by $40 \%$ and the total strain energy by $90 \%$ when compared to a bare hull with no control surfaces fitted.
\end{abstract}

\section{Keywords}

Ride Control Systems; High-Speed Catamarans; Model Test; Control Algorithm; Slam Energy

\author{
Abbreviations \\ AMC Australian Maritime College \\ RAO Response Amplitude Operator \\ RCS Ride Control System
}




\section{Nomenclature}

$C_{L \alpha} \quad$ Control surface lift coefficient derivative $\left(d C_{L} / d \alpha\right)$ (dimensionless)

E $\quad$ Elastic modulus $\left(\mathrm{N} / \mathrm{m}^{2}\right)$

$E_{\varepsilon} \quad$ Elastic link strain energy (J)

$f_{e} \quad$ Wave encounter frequency $(\mathrm{Hz})$

$\mathrm{Fr} \quad$ Froude number based on hull waterline length

$H \quad$ Model heave at LCG (m, positive up)

$h \quad$ Cross-section height of elastic link (m)

$h_{\max } \quad$ Maximum relative bow immersion (m)

$h_{s} \quad$ Relative bow immersion at the instant of peak sagging slam force (m)

I Second moment of area of cross section $\left(\mathrm{m}^{4}\right)$

$I_{s} \quad$ Water entry impulse (Ns)

$k_{\text {eff }} \quad$ Effective stiffness of elastic link ( $\left.\mathrm{Nm} / \mathrm{rad}\right)$

$k_{t h} \quad$ Theoretical stiffness of elastic link $(\mathrm{Nm} / \mathrm{rad})$

LCG Longitudinal Centre of Gravity

$l_{b} \quad$ Length of elastic link (m)

$M \quad$ Bending moment (N.m)

$P \quad$ Model pitch about LCG (radian, positive bow down)

$S_{S T} \quad$ Stern tab planform area $\left(\mathrm{m}^{2}\right)$

$S_{T F} \quad$ T-Foil planform area $\left(\mathrm{m}^{2}\right)$

$x_{S T} \quad$ Distance between centre of pressure of the stern tabs and LCG (m)

$x_{T F} \quad$ Distance between centre of pressure of the T-Foil and LCG (m)

$V_{\max } \quad$ Maximum relative bow velocity $(\mathrm{m} / \mathrm{s})$

$V_{s} \quad$ Relative bow velocity at the instant of peak sagging slam force $(\mathrm{m} / \mathrm{s})$

$\alpha_{S T d} \quad$ Control system demand stern tabs angular deflection (radian, positive producing upward lift)

$\alpha_{T F d} \quad$ Control system demand T-Foil angular deflection (radian, positive producing upward lift)

$\varepsilon \quad$ Differential strain measured on elastic link

$\Delta t_{s} \quad$ Water entry impulse integration time (s) 
$\omega_{e} \quad$ Angular wave encounter frequency $=2 \pi f_{e}(\mathrm{rad} / \mathrm{s})$

$\omega_{e}{ }^{*} \quad$ Dimensionless angular wave encounter frequency $=\omega_{e} \sqrt{L / g}$

\section{Introduction}

Ride control systems (RCS) are critical to reducing the motions of high-speed craft, which often exceed those of conventional ships due to their slender hulls and high Froude number of operation [1-3]. In addition, catamaran vessels operating at high speed often experience slam events and associated large wave loads when the vessel motion causes an impact between the cross deck structure and the water surface [4]. INCAT Tasmania [5] uses active motion control systems in many of its high-speed wave piercing catamarans to reduce vessel motions and dynamic structural loads, improve passenger comfort and increase the range of operability [3, 6]. These active Ride Control Systems consist of a retractable T-Foil mounted on the centreline at the aft end of the centre bow and two active trim tabs located at the stern of the vessel demi-hulls.

A comprehensive literature review of RCS has been previously presented by the authors [7, 8]. Although some studies on ship motions and motion control systems have been undertaken by numerical computations, experimental investigations and full-scale sea trials [9-33], there is still limited knowledge on the mechanisms of the whole motion control system and to date there has been little published work on their optimum mode of operation. In order to understand and optimise the motion control system experimental investigations are required to accurately determine the effect of the control system on the ship motions and loads.

The model ride control system for the wave piercing catamaran (WPC) studied in the present work consisted of a T-Foil located close to the aft end of the short central bow and two stern tabs, one on each demihull. Figure 1 (a) shows the T-Foil installed on the aft section of the centre bow of the catamaran model while Figure 1 (b) shows the stern tabs installed at the stern of the catamaran model. The model is constructed in segments connected by flexible links so as to correctly simulate full scale whipping vibration and to facilitate measurement of dynamic bending loads [34]. Figure 1 (c) shows the overall layout of the catamaran model, constructed in separate segments connected by aluminium elastic links with attached strain gauges to facilitate measurement of vertical bending moment at the link [34]. 
Lift and drag characteristics as well as frequency response of the model scale low Reynolds number T-Foil were previously investigated by both static and dynamic tests [35] in a circulating water tunnel to determine the performance characteristics of the foil. The model scale T-Foil has an aspect ratio of 3.6 and operates at a Reynolds number of approximately $10^{5}$. It was concluded from this previous study [35] that the low Reynolds number model scale T-Foil with a relatively low aspect ratio had an adequate unsteady performance for application to a $2.5 \mathrm{~m}$ catamaran model for tests to be undertaken in the Australian Maritime College (AMC) towing tank. Lifting performance and pressure distribution of the model scale stern tabs have also been investigated [30, 36].

The step and frequency responses of the $2.5 \mathrm{~m}$ wave piercing catamaran model to the ride control system has been investigated by calm water open-loop testing with forward speed at the AMC towing tank [37]. An appropriate combination of control movements to excite the model only in heave or only in pitch was found by this study forming the basis of setting the gains of the ride control system for the pitch control, local motion control and heave control in preparation for the model tests in head-seas.

The effect of the ride control algorithms on the motions of a $112 \mathrm{~m}$ high-speed wave-piercing catamaran in waves has been investigated by the authors [7]. The design and open loop performance of a model scale ride control system fitted to the $2.5 \mathrm{~m}$ hydroelastic catamaran model was first considered, identifying the method of operation required to produce any desired combination of pure heave and pitch control. Dynamic response of the model scale RCS was investigated and a $5 \%$ reduction in amplitude and $15^{\circ}$ phase shift of the control surfaces relative to the demand deflection input signal were identified at the upper end of the required test frequency range.

Six active modes of closed-loop feedback operation were then to be investigated: local control surface vertical motion feedback, heave and pitch feedback, each in a linear and nonlinear application. The control performance is then to be compared to passive operation and to the bare hull response at two wave heights and for a wide range of wave encounter frequencies, against a variety of criteria including motion and acceleration feedback. As will be seen in the present paper the ride control system can significantly reduce the model motions. This was most evident in the nonlinear pitch control mode, where the maximum pitch Response Amplitude Operator (RAO) was reduced by up to $50 \%$ in $2.69 \mathrm{~m}$ (full scale equivalent) waves and the vertical acceleration near the bow by about $40 \%$ under the same model test conditions [7]. These results clearly demonstrated that significant gains could be achieved through the implementation of a ride control system with regard to reduction of wave impact slamming. 
The other study by the authors [8] investigated the influence of the ride control system on the structural loads, including vertical bending moments and wave induced slam loads on the central bow. From this investigation it was found that the pitch control mode was indeed the most effective and in $60 \mathrm{~mm}$ model scale waves (full scale 2.69 m) it significantly reduced the peak slam force by up to $90 \%$ and the average slam induced bending moment by up to $75 \%$, when compared to a bare hull with no ride controls fitted [8]. This clearly demonstrated the effectiveness of a ride control system in reducing wave impact loads on high-speed catamarans that could be a significant consideration for the future design of this type of vessel.

The present study extends these investigations to evaluate the influence of control algorithms on the slamming kinematics, water entry impulse and energy transfer acting to the $2.5 \mathrm{~m}$ hydroelastic segmented catamaran model. The key relationships between the immersion and relative velocity of the bow relative to the undisturbed encountered wave profile and the peak sagging slam force are identified. Several aspects of the loading and relative motion of the bow are considered in the present paper. Firstly, the bow entry process is investigated to evaluate the key kinematic parameters that determine the consequent wave slamming loads. Secondly, the water entry impulse of the transient upward force acting on the bow is investigated in order to evaluate the effect of slamming on the overall vessel motion. Thirdly, the energy imparted to the vessel structure at the peak slamming load is evaluated in terms of the strain energy transferred into the main hull whipping mode of vibration. These three aspects are considered using the methods previously described by Lavroff and Davis [38] for a bare hull with no RCS.

\section{Ride control algorithms}

The towing tank model testing was performed with different ride control conditions including without RCS, passive RCS and active RCS. The active RCS modes consisted of heave motion control, local motion control and pitch motion control, while linear and nonlinear gains were applied for each control mode. In essence the intent here was to introduce damping to the hull motion by the RCS producing control loads to oppose either heave velocity, pitch rate or local vertical velocity of each control surface. Gains were set to use the full range of control surface amplitudes, the gains being higher in smaller seas. Linear gains ensured that control deflections only just reached maximum possible amplitudes whereas nonlinear gains always employed maximum up or down control forces subject to the constraint of the control surface slew rates (approximately $300^{\circ} / \mathrm{s}$ ) between these conditions. Whilst the intent of the model RCS feedback settings was to produce motion damping, significant phase shifts in the small model scale feedback system resulted in control actions which effectively included additional motion stiffness 
effects $[7,8]$. As will be seen this was a beneficial aspect of the model RCS system. The small phase shifts in the electronic control surface activation system increased with frequency and thus appeared to originate in a time delay in the model RCS electronic feedback system [7, 8].

For the pitch damping control mode, the demanded control deflections can be formulated as a pitch damping demand [7] with

$\alpha_{T F d}=e \dot{P}$

$\alpha_{S T d}=k \dot{P}$,

where $\alpha_{T F d}$ and $\alpha_{S T d}$ are the demanded angle of attack deflections of the T-Foil and stern tabs respectively, and $\dot{P}$ is the pitch velocity. As mentioned in the previous paragraph, the actual deflections are somewhat phase lagged from these demands.

To ensure that zero net heave force is generated by the controls in pitch control mode, the gains $k$ and $e$ must have a defined ratio. The parameter $e$ governs the t-foil deflection and is here determined first. For linear feedback deflection of the T-Foil $e$ is determined so as to cause the control surface to operate over its maximum range of deflection as

$e=-\frac{\left(\alpha_{T F d}\right)_{\max }}{\dot{P}_{\max }}$

The value of the gain $e$ is thus determined from the known maximum T-Foil deflection and an estimated maximum pitch rate [7]. The maximum pitch rate can be estimated from the wave encounter angular frequency, the estimated maximum pitch RAO and the Froude number.

The demand signals input to the control surfaces and their consequent change of angle of attack thus determine the demanded excitation forces applied to the hull by the ride control surfaces in heave and pitch [7, 35, 37].

In the pitch control mode zero heave is sought and thus the required control parameter $k$ for the linear deflection of stern tabs [7] for which there is no net vertical heave force on the hull due to the ride controls is then

$k=-e \frac{S_{T F}\left(C_{L \alpha}\right)_{T F}}{2 S_{S T}\left(C_{L \alpha}\right)_{S T}}$.

The control surfaces lift coefficient derivatives $\left(C_{L \alpha}\right)$ were determined from previous studies on the T-Foil [35] and stern tabs [30].

For the heave control mode the demanded control deflections are

$\alpha_{T F d}=b \dot{H}$ 
$\alpha_{S T d}=h \dot{H}$.

where $\dot{H}$ is the heave velocity. In this case the parameter $b$ governs the T-Foil defection and follows from the maximum deflection of the T-Foil and the estimated maximum heave velocity as

$b=-\frac{\left(\alpha_{T F d}\right)_{\max }}{\dot{H}_{\max }}$.

For the heave damping control mode the total pitch moment about the LCG induced by the control surfaces must be zero and thus

$h=b \frac{x_{T F} S_{T F}\left(C_{L \alpha}\right)_{T F}}{x_{S T} 2 S_{S T}\left(C_{L \alpha}\right)_{S T}}$,

where $x_{T F}$ and $x_{S T}$ are the absolute distances from the LCG to the centres of pressure of the T-Foil and the stern tabs respectively; these are assumed to be forward and aft of the LCG respectively.

In local damping control mode the control surfaces act independently and have input demands to oppose the local vertical velocity at each control surface location. The hypothesis here is simply that this action extracts maximum energy due to effective local motion damping at the control position for any dynamic motion of the hull. The vertical velocities of the model at the longitudinal location of each control surface are $\dot{H}-x_{T F} \dot{P}$ and $\dot{H}+x_{S T} \dot{P}$ for the TFoil and stern tab respectively. Thus in the local damping control mode we require control surface demands $\alpha_{T F d}=$ $b\left(\dot{H}-x_{T F} \dot{P}\right)$ and $\alpha_{S T d}=h\left(\dot{H}+x_{S T} \dot{P}\right)$, where

$b=-\frac{\left(\alpha_{T F d}\right)_{\max }}{\dot{H}_{\max }}$

$h=-\frac{\left(\alpha_{S T d}\right)_{\max }}{\dot{H}_{\max }}$.

Thus

$e=-b \times x_{T F}$

$k=h \times x_{S T}$

It is recognised that the control surfaces are not large enough to cancel motions altogether in large waves; therefore a nonlinear version of each algorithm is introduced [7]. In each nonlinear control mode the control surfaces are moved to their maximum angular offsets as quickly as the mechanisms will allow [37], thus giving demand control surface deflections
$\alpha_{T F d}= \pm\left(b \dot{H}_{\max }+e \dot{P}_{\max }\right)$
(13) and
$\alpha_{S T d}= \pm\left(h \dot{H}_{\text {max }}+k \dot{P}_{\text {max }}\right)$. 
The constants $b, e, h$ and $k$ are determined in the same way as for each linear control action so that the maximum lift force or moment opposes the relevant velocity term (heave, pitch or local). Thus the maximum control forces at the extreme point of motion velocity will remain unaltered but the forces or moments opposing the velocities will remain at the maximum for a longer duration within the motion half cycles [7].

\section{Time record data analysis}

Towing tank testing in head seas was undertaken in regular head sea waves at a model speed of $2.89 \mathrm{~m} / \mathrm{s}$, simulating a full scale speed of 37 knots, with a displacement of $28.3 \mathrm{~kg}$, corresponding to a full scale displacement of 2545 tonnes. The model was tested at two wave heights, $60 \mathrm{~mm}$ and $90 \mathrm{~mm}$, simulating full scale wave heights of $2.69 \mathrm{~m}$ and $4.03 \mathrm{~m}$ respectively. Model scale wave frequencies ranging from $0.350 \mathrm{~Hz}$ to $0.900 \mathrm{~Hz}$ were generated by the towing tank wave maker for each test condition $[7,8]$.

The strain gauge data and the motion data were acquired simultaneously in order to investigate the key kinematic parameters controlling the slamming process. Figure 2 shows a typical time record at a model speed of $2.89 \mathrm{~m} / \mathrm{s}$ (Fr $=0.608$ ), wave height of $90 \mathrm{~mm}$ and dimensionless wave encounter frequency, $\omega_{e}^{*}=4.581$ for the pitch control mode of operation of the ride control system (RCS). The kinematic parameters including bow height, bow immersion and relative bow velocity are measured at the longitudinal location of the T-Foil (which is close to the centre bow truncation on the hull centre line where the slam force is generally found to act [37]) and are relative to the undisturbed incident wave profile. The water surface elevation is not measured directly through the model tests, but is derived from the recorded model motion, forward speed and water surface vertical motions measured at other locations as discussed in the following sections. It should be noted that the wave profile elevation at the LCG, bow height, centre bow total force and the heave motion are all positive upwards, the pitch motion and the relative bow velocity are positive bow down and the control surfaces deflection are positive counter-clockwise viewed from the starboard side, producing upward lift.

In order to evaluate the extremes of the observed signals, a range of the time record was analysed, starting when regular periodic motions had been reached during a run along the towing tank and including at least five cycles. An average of the extremes of all these cycles is then presented. This analysis was carried out by finding the peak and trough of each cycle. 
The accuracy of the results was established by uncertainty analysis based on the standard deviation of the observations. For each run the time record included from 5 to 19 useable cycles after transients had dissipated and before either the run terminated or wave reflections or other forms of contamination became significant. The variation between the cycles in each run was analysed in order to quantify the accuracy of the results. The standard deviation analysis of the results shows an average of $\pm 2.5 \%$ variation, demonstrating that the uncertainty in the results is insignificant compared to the overall effect of the ride control system. Thus the experimental uncertainty has no impact on the key conclusions of this research $[7,8]$.

\section{Response Amplitude Operators (RAOs)}

The heave and pitch motions were measured using the LVDT data obtained from the towing tank data acquisition system and from this the Response Amplitude Operators (RAOs) were evaluated. Figure 3 shows the heave and

pitch RAOs with pitch control feedback. The dimensionless wave encounter angular frequency is $\omega_{e}^{*}=2 \pi f_{e} \sqrt{\frac{L}{g}}$ where $f_{e}(\mathrm{~Hz})$ is the wave encounter frequency and $L$ is the overall hull length. These results show the extremes of RAO observed with either the bare hull without RCS or with the RCS operating in pitch control or nonlinear pitch control modes. Other feedback modes (heave control, local control) were found to give intermediate RAO results that were generally closer to the bare hull response [7]. Deployment of the T-Foil to a fixed position and acting as a passive control surface was found to moderately reduce the peak heave and pitch motions. We see in Figure 3 that the heave RAO is not greatly influenced by the RCS in the pitch control mode as would be expected, although at low frequency the RCS does increase the heave motion slightly compared to the bare hull with no RCS. However, the pitch RAO is substantially reduced, and to a greater degree in small waves where the RCS gains can be higher whilst keeping the RCS movement within the overall mechanical limits. In the pitch control mode the peak pitch motion is reduced by up to $50 \%$ in the lower range of encounter frequency. Of particular note is the substantial reduction of pitch motion achieved in this lower range of wave encounter frequency, this being a result of model system phase lags contributing effective pitch stiffness in the feedback system. In these longer, low frequency encountered waves the hull motion is nearly quasi-static and the RCS has moderate capacity to partly trim the hull level throughout the wave encounter cycle. We also see that operation in nonlinear mode further decreases the pitch RAO since the controls then oppose pitch motion at maximum deflection for a greater proportion of the wave encounter period. The reduction in pitch motion is greatest in smaller, longer waves where the RAO is reduced by up to $70 \%$ compared to the bare hull configuration with no RCS fitted. 


\section{Acceleration response}

Passenger comfort depends primarily on the vertical accelerations, which can be quite different at different locations on the hull depending on the magnitudes and relative phase of heave and pitch motions. The vertical motion acceleration of the catamaran model was investigated at three different longitudinal locations: the location of the TFoil ( $80 \%$ of LOA from the stern), LCG (37\%) and the location of the stern tabs. The location of the T-Foil and the stern tabs represent approximate extreme forward and aft locations for passengers. Figure 4 shows the dimensionless vertical acceleration at the longitudinal location of the T-Foil at wave heights of $60 \mathrm{~mm}$ and $90 \mathrm{~mm}$, this being the location of the most severe motions of the three positions.

We see that the pitch control mode reduced these forward accelerations by approximately $40 \%$ in the smaller waves whilst there was a smaller percentage reduction of about $25 \%$ in the larger waves. The resulting dimensionless accelerations at this location were somewhat similar at around 31-35 for both wave heights and for both linear and nonlinear feedback conditions.

\section{Effect of ride control system on slam loading}

The hydroelastic model comprised seven segments: three longitudinal segments for each demi-hull and a separate centre bow. The segments were connected by elastic links tuned to replicate the first longitudinal bending mode natural frequency at full scale and to facilitate measurement of dynamic bending $[34,39,40]$. The effect of the ride control system on the model slam loading was investigated by analysing the dynamic data obtained from the strain gauges installed on the model centre bow and demi-hull links [8]. Figure 5 shows the centre bow peak slam force at wave heights of $60 \mathrm{~mm}$ and $90 \mathrm{~mm}$. The peak force may be decomposed into an upward force on the centre bow due to its increasing immersion prior to the slam, and the actual slam force which occurs rapidly when the rising water surface reaches the top of the arch between centre bow and demi-hulls and fills the arch cross section. The actual slam force is approximately $65 \%$ of the total transient force shown in Figure 5. The pitch control mode reduced the peak slam force by about $90 \%$ in $60 \mathrm{~mm}$ waves, effectively eliminating slamming in these smaller waves.

Figure 6 shows the sagging slam induced bending moments measured on the elastic links joining the forward and central demi-hull segments of the catamaran model ( $57 \%$ of LOA from the stern). Moments are plotted as a function of wave encounter frequency at wave heights of $60 \mathrm{~mm}$ and $90 \mathrm{~mm}$. As can be seen from Figure 6, both linear and 
non-linear pitch control modes show a substantial reduction of about $75 \%$ in the peak sagging forward segment link bending moments in the smaller waves, the slam component being effectively eliminated. The pitch control mode reduced the sagging forward link peak bending moments by about $30 \%$ at the larger wave height of $90 \mathrm{~mm}$, where slamming was not eliminated.

\section{Ride Control System, motion kinematics and slamming}

The slamming kinematics results for the catamaran model were investigated by measuring the centre bow motion, noting that slam forces occur close to the aft end of the central bow of the WPC [8]. The centre bow motion at the location of the T-Foil (1990 $\mathrm{mm}$ from the transom, close to the centre bow truncation) relative to the undisturbed incident wave profile during the slamming process was investigated by using the heave and pitch motions data obtained during towing tank tests performed in regular seas. The same analytical procedure was used as previously described by Lavroff [38], who developed a set of measurable kinematics parameters, investigating the relative bow immersion, relative bow velocity and the peak sagging slam force. These parameters were used to identify key relationships during the highly nonlinear wave slamming process. Furthermore, data trends were identified between the slam force, water entry impulse and energy transfer to hull whipping and the maximum relative bow velocity to determine the relationships existing between the kinematic parameters and slam loading parameters.

Figure 7 shows the kinematic parameters identified for the analysis of the relative bow immersion and relative bow velocity, and their relationship to the centre bow total force. This figure shows data obtained at a model test speed of $2.89 \mathrm{~m} / \mathrm{s}$, wave height of $90 \mathrm{~mm}$ and dimensionless wave encounter angular frequency, $\omega_{e}^{*}=6.272$ with the application of the RCS in pitch control mode. The maximum arch height was measured from the undisturbed calm water line to the highest point on the arched cross sectional profile between the outboard hulls and the central bow. The relative bow immersion was evaluated directly by subtracting the measured undisturbed wave elevation from the absolute bow height, both evaluated (as per Figure 2) at the longitudinal location of the T-Foilclose to the center bow truncation where most slam force resultants are located. The relative bow velocity was calculated from the relative bow immersion using numerical differentiation with respect to time [38]. Other quantities introduced in Figure 7 are defined as: relative bow immersion $h_{\max }$, relative bow immersion at the instant of the peak sagging slam force $h_{s}$, maximum relative bow velocity $V_{\max }$, relative bow velocity at the instant of the peak sagging slam force $V_{s}$ and water entry impulse integration time $\Delta t_{s}$. These parameters will be discussed in more detail in sections 7.1 to 7.3. 
The centre bow total force and the kinematic data were then analysed in order to investigate the relationship between the wave induced slam forces and the kinematics of the centre bow relative motion. It should be noted that the model motions data was sampled at $50 \mathrm{~Hz}$, while the sample rate of the loads data was $1.613 \mathrm{kHz}$. Figures 8 to 16 show the slamming kinematic results.

\subsection{Relative bow immersion with active RCS}

Figures 8 (a) and (b) show the maximum relative bow immersion for the entire slam event, $h_{\max }$, at wave heights of $60 \mathrm{~mm}$ and $90 \mathrm{~mm}$ respectively. Comparing Figures 8 (a) with 8 (b), it can be seen that increases in the wave height gave rise to larger relative bow immersion, $h_{\max }$.

These results show that ride control system does not have a strong influence on the maximum relative bow immersion, $h_{\max }$. However, the pitch control mode still is the most effective motion control algorithm. The maximum bow immersion with this RCS algorithm approaches the arch height, but (as shown in Section 7.2) the slam develops from a lower maximum relative velocity, suggesting a more controlled deceleration. On the other hand, without RCS there is a significant relative velocity as the immersion approaches the arch height, but large forces are in this case developed due to the arch filling slam process, preventing the maximum immersion increasing much beyond this point.

Figures 9 (a) and (b) show the relative bow immersion at the instant of the peak sagging slam force, $h_{s}$ at wave heights of $60 \mathrm{~mm}$ and $90 \mathrm{~mm}$ respectively. As can be seen from Figure 9 (a), $h_{s}$, at a wave height of $60 \mathrm{~mm}$ was less than the maximum arch height for all ride control conditions, indicating that the peak sagging slam force occurred prior to the undisturbed water level reaching the top of the arch; this demonstrates that the slam involves significant upward displacement of the undisturbed water surface by the entry of the demi-hulls and centre bow and that the RCS is most effective in the non-linear pitch control mode. Although all ride control conditions show broadly similar results for the relative bow immersion at the instant of peak sagging slam force, the pitch control mode shows the lowest bow immersion, especially for dimensionless wave encounter frequencies between 4 to 6 .

Comparing Figure 9 (a) with Figure 9 (b), it is observed that increases in the wave height gave rise to only a modest increase of the bow immersion at the instant of the peak sagging slam force, $h_{s}$, although the bow immersion is seen to approach and exceed the maximum arch height in $90 \mathrm{~mm}$ waves which was not the case in $60 \mathrm{~mm}$ waves.

\subsection{Relative bow velocity with active RCS}


Figures 10 (a) and (b) show the maximum relative bow velocity, $V_{\max }$, for wave heights of $60 \mathrm{~mm}$ and $90 \mathrm{~mm}$ respectively. It can be seen from Figures 10 (a) and (b) that the maximum relative bow velocity was significantly decreased by decrease of wave height, as previously identified for a bare hull with no RCS by Lavroff [38]. Furthermore, when comparing these results with the slam force results presented in Figure 5, the maximum relative bow velocity shows a similar trend of variation to the maximum slam forces.

It is observed from Figure 10 (a) that the ride control system, especially in the pitch control mode, can significantly reduce the maximum relative bow velocity at a wave height of $60 \mathrm{~mm}$, whereas the results in Figure 10 (b) demonstrates that the ride control system has a lesser effect on the maximum relative bow velocity at a wave height of $90 \mathrm{~mm}$. This is because the control gains employed were those that gave the maximum deflection of the control surfaces irrespective of the wave heights, so that the controls have a more limited effect in larger waves.

Figures 11 (a) and (b) show the relative bow velocity at the instant of the peak sagging slam force, $V_{s}$, at wave heights of $60 \mathrm{~mm}$ and $90 \mathrm{~mm}$ respectively. Comparing these results with the results presented in Figures 10 (a) and (b), it can be seen that the relative bow velocity at the instant of peak sagging slam force was significantly less than the maximum relative bow velocity for most test conditions. In fact the relative velocity at the instant of the slam was in many cases close to zero, as also observed by Lavroff [38].

\subsection{Slam duration and water entry impulse with active RCS}

In order to evaluate the water entry impulse, an integration time of $\Delta t_{s}$ was chosen for the evaluation of the impulse as shown in Figure 7. This was defined to be from the zero crossing of the centre bow total force immediately before the peak slam to the zero crossing immediately after. Note that an average of several slam events was used and so the force values at either end of this interval shown in Figure 7 are not exactly zero. The force drops abruptly after the peak so the integration end time is quite precisely determined, but the rise is more gradual so the integration start time is less precise. However most of the integration area is under the force peak and small variations in the integration time limits have negligible effect on the results.

Figures 12 (a) and (b) show the water entry impulse integration time, $\Delta t_{s}$, for wave heights of $60 \mathrm{~mm}$ and $90 \mathrm{~mm}$ respectively. These results show that the water entry impulse integration time was relatively constant for all the test conditions. It is also seen that the time was slightly shorter at the higher wave height. This is a consequence of the 
higher relative velocity combined with the conclusion reached in Section 7.1 that the bow immersion was largely limited by the arch height.

Figures 13 (a) and (b) show the absolute water entry impulse, $\left|I_{s}\right|$, at wave heights of $60 \mathrm{~mm}$ and 90 mm respectively. Comparing these results with the slam force results presented in Section 6, similarities between the frequency responses of the water entry impulse and the slam force can be observed. This is expected given that the water entry impulse duration was relatively constant. Figures 13 (a) and (b) show that increases in the wave height gave rise to similar frequency dependencies of the magnitude of the water entry impulse and the peak sagging slam forces. It is observed that the peak water entry impulses measured during each test condition occurred at approximately the same dimensionless wave encounter frequencies as the peak slam forces due to the small variation of water entry impulse integration times as presented in Figure 12. As can be seen from Figures 13 (a) and (b), the ride control system significantly reduced the water entry impulse. The nonlinear pitch control algorithm gave a $40 \%$ reduction in the water entry impulse relative to no RCS in $60 \mathrm{~mm}$ waves. However, the nonlinear local control algorithm gave a $65 \%$ reduction in the water entry impulse relative to no RCS in $60 \mathrm{~mm}$ waves. This may be attributed to the effect of the T-Foil in reducing motion at its location, close to the location of the slam force.

\section{Slam induced strain energy analysis}

It is of interest to investigate the strain energy imparted by wave slam into the main whipping mode, which can be determined by the maximum bending of the elastic links. This is a measure of the potential for structural damage due to deformation during the slam, and due to fatigue associated with structural vibration, primarily whipping in this case.

In order to identify relationships between the centre bow water entry impulse, slamming kinematic data and the total strain energy, the slam induced strain energy was evaluated for all model test conditions using the method developed by Lavroff [38]. Since the flexibility in the model hull is concentrated at the elastic links the elastic strain energy can be recorded by the deformation at these points. Away from the elastic links the model hull is effectively rigid, and does not experience significantly higher bending moments and so cannot store significant strain energy.

As described by Lavroff [38], the strain energy of an elastic link is $E_{\varepsilon}=M \theta / 2$, which is the work done by the applied moment $M$ in producing a relative link angular deflection $\theta$. This may be written as $E_{\varepsilon}=M^{2} / 2 k_{\text {eff }}$, where 
$k_{\text {eff }}=M / \theta$ is the link's effective stiffness, determined during the link calibration process under applied static loads. $M$ in turn is obtained from the differential strain $\varepsilon$, measured between the elastic link upper and lower surfaces, as $M=k_{\mathrm{th}} l_{b} \varepsilon / h$, where $k_{\mathrm{th}}=E I / l_{b}$ is the elastic link theoretical stiffness (which differs slightly from the effective stiffness due to end effects on the elastic link beam element and the model global flexibility [41]), $l_{b}$ is the length of the elastic link beam element, and $h$ is the cross-section height of the elastic link beam. Thus, the strain energy of an elastic link can be evaluated from the strain records by

$E_{\varepsilon}=\left(\frac{l_{b}^{2}}{2 h^{2}} \frac{k_{\mathrm{th}}^{2}}{k_{\mathrm{eff}}}\right) \varepsilon^{2}$

Strain energy was recorded in the eight elastic links: four in the two demi-hulls and four in the transverse bow mounting beams. The latter are much stiffer and so absorb a relatively small part of the total energy stored. The peak strain energy of the centre bow and demi-hull elastic links were evaluated for all the ride control conditions in order to identify the effect of the ride control system on the total slam induced strain energy. The average peak sagging slam energy was calculated for each model test run by averaging the peak values of at least five cycles of regular motion. Figures 14 to 16 show the peak strain energy of the centre bow links, demi-hull links and total peak strain energy in $60 \mathrm{~mm}$ and $90 \mathrm{~mm}$ waves as a function of dimensionless wave encounter frequency. It should be noted that different scales of vertical axis are used for the $60 \mathrm{~mm}$ and $90 \mathrm{~mm}$ wave results in Figures 15 and 16 in order to clearly show the detail of results.

The peak strain energy of the centre bow transverse mounting beam elastic links is shown in Figures 14 (a) and (b) for wave heights of $60 \mathrm{~mm}$ and $90 \mathrm{~mm}$ respectively. Comparing these with the total energy in Figure 16, it is seen that only a small proportion of the strain energy goes into the centre bow mountings. However, as can be seen from these figures, the peak strain energy of the centre bow elastic links does increase significantly with increase of wave height. The influence of wave encounter frequency on the slam induced strain energy is similar to that observed on the water entry impulse, shown in Figure 13, and is consistent with the results with no RCS presented by Lavroff [38]. Figures 14 (a) and (b) show that the pitch control mode was the most effective ride control algorithm for mitigation of the strain energy of the centre bow elastic links, which further confirms this as most effective RCS algorithm for mitigation of slamming [8].

Figures 15 (a) and (b) show the peak strain energy of the demi-hull elastic links at wave heights of $60 \mathrm{~mm}$ and $90 \mathrm{~mm}$ respectively. Comparing these figures with Figures 14 (a) and (b), it can be seen that substantially more 
strain energy goes into demi-hull bending than into the centre bow elastic links, as was also observed by Lavroff [38]. Figures 15 (a) and (b) show clearly that the pitch control mode most strongly reduced the strain energy imparted to the demi-hull elastic links. The reduction between no RCS and both linear and nonlinear pitch control in $60 \mathrm{~mm}$ waves is particularly noteworthy, this being a reduction of about $90 \%$ in demi-hull whipping strain energy.

Finally, Figures 16 (a) and (b) show the total peak strain energy of the centre bow and demi-hull elastic links at wave heights of $60 \mathrm{~mm}$ and $90 \mathrm{~mm}$ respectively. It is observed from Figure 16 (a) that the ride control system even in the passive mode can significantly reduce the total strain energy imparted to the catamaran model. Although similar results can be seen at a wave height of $90 \mathrm{~mm}$, presented in Figure 16 (b), the pitch control algorithm demonstrates the greatest reduction of the total slam induced strain energy at a wave height of $60 \mathrm{~mm}$ and to a lesser degree at a wave height of $90 \mathrm{~mm}$.

\section{Conclusions}

It has been found that the ride control system significantly reduces the peak heave and pitch motions of the highspeed catamaran model. This was most evident in the pitch control mode, which substantially reduced the peak pitch motion by about $70 \%$ in $60 \mathrm{~mm}$ waves at model scale $(2.69 \mathrm{~m}$ full scale). The ride control system in the pitch control mode also significantly reduced the local vertical acceleration of the model near the bow by around $40 \%$ in $60 \mathrm{~mm}$ waves at model scale. The acceleration response of the catamaran model to the ride control system showed the potential for substantial improvement of passenger comfort and reduction of structural loads, particularly with nonlinear pitch control in the lower range of wave encounter frequency. The results also show that the ride control system can reduce the centre bow slam force most strongly in the pitch control mode, where it reduced the peak slam force by up to $90 \%$ and the slam induced bending moments by up to $75 \%$ in the smaller 60 mm waves at model scale compared to the model with no ride control system.

The effect of the RCS on the kinematics of slamming was investigated and confirmed the benefit of the RCS in the reduction of relative motion and mitigation of slamming. Whilst there was some reduction in relative motions, there were some aspects of the slamming kinematics that remained not greatly affected. In particular, the ride control system did not significantly affect the maximum relative bow immersion during the entire slam event. However, the relative bow immersion at the instant of the peak sagging slam force at a wave height of $60 \mathrm{~mm}$ was less than the maximum arch height for all ride control conditions, indicating that the peak sagging slam force at this wave height occurred prior to the undisturbed water level reaching the top of the arch. This shows the effect of uplift of the water 
surface above the undisturbed wave profile, caused by displacement of water by the centre bow and demi-hulls as they enter the water. The relative bow immersion at the instant of peak sagging slam force increased at the larger wave height of $90 \mathrm{~mm}$ (4.03 $\mathrm{m}$ full scale) and in that case the immersion reached the arch clearance in the midrange of encounter frequency for which maximum bow motions occurred. Increase of the wave height also gave rise to an increase of the maximum relative bow velocity. The relative bow velocity at the instant of the peak sagging slam force was significantly less than the maximum relative bow velocity for most ride control conditions. In most cases investigated, the RCS algorithms gave rise to a significant reduction in relative motion and this directly influenced the strain energy imparted to the model. The nonlinear pitch control algorithm was most effective in this respect.

The water entry impulse imparted by the slam events was reduced by up to $40 \%$ compared to the hull with no RCS. The maximum water entry impulse at full scale on a $112 \mathrm{~m}$ vessel would thus be reduced from 368 tonne seconds without the RCS to 220 tonne seconds with the RCS operating in nonlinear pitch control mode. As in previous research it was found that most of the slam induced strain energy was transmitted to the demi-hulls. The RCS demonstrated a reduction in the total strain energy depending on the algorithm used. In particular, the RCS in the pitch control mode was the most effective method for reducing the total peak strain energy in both $60 \mathrm{~mm}$ and 90 $\mathrm{mm}$ waves. There was a considerable reduction by the RCS of the strain energy imparted during wave slamming by up to $90 \%$ compared to the hull with no RCS. The maximum strain energy at full scale for the $112 \mathrm{~m}$ INCAT vessel would thus be reduced from $0.72 \mathrm{MJ}$ without the RCS to $0.07 \mathrm{MJ}$ with the RCS operating in nonlinear pitch control mode.

It is clear from the kinematics results presented that the ride control system, especially when running in the pitch control mode, can significantly reduce the motions and the loads acting on the WPC hull. Substantial reductions in impulse and strain energy transfer from water entry to the ship structure can also be achieved. In these model tests the RCS pitch control algorithm was effectively a combination of pitch stiffness and pitch damping feedback owing to phase shifts in the model system. Reductions in motion were greatest in the lower range of encounter frequency. This is a significant outcome as the dominant motions experienced by passengers are in response to waves somewhat longer than the hull.

The outcomes of this work have thus identified opportunities for improving the design of future high-speed catamarans. In particular it is possible to significantly reduce the vessel motions to improve passenger comfort and 
also to reduce the loads sustained by the vessel. This will potentially enable ship designers to develop a more efficient structural design, thereby increasing the payload of the vessel and reducing the costs of manufacture.

\section{Acknowledgements}

This project is supported by Australian Research Council Linkage grant No. LP-0883540. The support of INCAT Tasmania Pty. Ltd., Revolution Design Pty. Ltd., the University of Tasmania, and the Australian Maritime College is gratefully acknowledged.

\section{References}

[1] G. Thomas, S. Winkler, M. Davis, D. Holloway, S. Matsubara, J. Lavroff, and B. French, "Slam events of high-speed catamarans in irregular waves," Journal of Marine Science and Technology, vol. 16, pp. 8-21, Mar 2011.

[2] M. R. Davis and D. S. Holloway, "Motion and passenger discomfort on high speed catamarans in oblique seas," International shipbuilding progress, vol. 50, pp. 333-370, 2003.

[3] G. Jacobi, G. Thomas, M. Davis, D. Holloway, G. Davidson, and T. Roberts, "Full-scale motions of a large high-speed catamaran: The influence of wave environment, speed and ride control system," International Journal of Maritime Engineering, vol. 154, pp. A143A155, 2012.

[4] G. Thomas, M. Davis, D. Holloway, T. Roberts, S. Matsubara, J. Lavroff, W. Amin, K. Chamberlin, and T. Dove, "Characterisation of slam events of a high-speed catamaran in irregular waves," in FAST: International Conference on Fast Sea Transportation, Athens, Greece, 2009, pp. 177-188.

[5] http://www.incat.com.au/\#. (2018).

[6] G. Jacobi, G. Thomas, M. R. Davis, and G. Davidson, "An insight into the slamming behaviour of large high-speed catamarans through full-scale measurements," Journal of Marine Science and Technology, vol. 19, pp. 15-32, Mar 2014.

[7] J. AlaviMehr, J. Lavroff, M. R. Davis, D. Holloway, and G. Thomas, "An Experimental Investigation of Ride Control Algorithms for High-Speed Catamarans Part 1: Reduction of Ship Motions," Journal of Ship Research, vol. 61, pp. 35-49, Mar 2017.

[8] J. AlaviMehr, J. Lavroff, M. R. Davis, D. S. Holloway, and G. A. Thomas, "An Experimental Investigation of Ride Control Algorithms for High-Speed Catamarans Part 2: Mitigation of Wave Impact Loads," Journal of Ship Research, vol. 61, pp. 51-63, Jun 2017.

[9] M. Bessho and Y. Kyozuka, "On the ship motion reduction by anti-pitching fins in head seas," in Naval Hydrodynamics, Fifteenth Symposium: Seakeeping Problems, Hullpropeller Interactions, Nonlinear Free-surface Problems, Frontier Problems in Hydrodynamics, 1985, p. 108.

[10] A. Haywood, A. Duncan, and K. Klaka, "The development of a ride control system for a surface effect ship. Interim report," Rep. CMST-C94-9, Curtin Univ., Perth, Australia, 1994. 
[11] A. Haywood, A. Duncan, K. Klaka, and J. Bennett, "The use of simulation in the development of a ride control system for fast ferries," in Proc. Conf. Maneuvering and Control of Marine Craft, Southampton, UK, 1994, pp. 261-269.

[12] A. J. Sorensen and O. Egeland, "Ride control of surface effect ships using distributed control," Modeling Identification and Control, vol. 15, pp. 65-79, Apr 1994.

[13] A. Haywood, A. Duncan, K. Klaka, and J. Bennett, "The development of a ride control system for fast ferries," Control Engineering Practice, vol. 3, pp. 695-702, 1995.

[14] C. Swanton, A. Haywood, and B. Schaub, "Simulation-an essential tool in the design of motion control systems," Proc. FAST'99, pp. 73-81, 1999.

[15] S. Esteban, J. M. Giron-Sierra, J. de la Cruz, B. De Andres, J. Díaz, and J. Aranda, "Fast ferry vertical accelerations reduction with active flaps and t-foil," in 5th IFAC Conference on Manoeuvring and Control of Marine Crafts MCMC2000, Aalborg, Denmark, 2000.

[16] S. Esteban, J. M. Giron-Sierra, J. De la Cruz, and B. D. A. Toro, "A computer based testbed for designing the control of vertical motions of a fast ferry," in Intl. Conf. on Marine Simulation and Ship Maneuvering, MARSIM, 2000, pp. 79-83.

[17] S. Esteban, B. De Andres, J. Giron-Sierra, O. Polo, and E. Moyano, "A simulation tool for a fast ferry control design," in Proc. IFAC Intl. Conf. Control Applications in Marine Systems, Glasgow, Scotland, 2001.

[18] J. Giron-Sierra, S. Esteban, B. De Andres, J. Diaz, and J. Riola, "Experimental study of controlled flaps and T-foil for comfort improvement of a fast ferry," in Proc. IFAC Intl. Conf. Control Applications in Marine Systems, Glasgow, Scotland, 2001.

[19] J. Tsai, J. Hwang, S. Chau, and S. Chou, "Study of hydrofoil assistance arrangement for catamaran with stern flap and interceptor," Fast sea transportation, FAST, 2001.

[20] S. Esteban, B. Andres-Toro, E. Besada-Portas, J. Giron-Sierra, and J. De la Cruz, "Multiobjective control of flaps and T-foil in high speed ships," in Proceedings IFAC 2002 World Congress, Barcelona, Spain, 2002.

[21] J. M. Giron-Sierra, R. Katebi, J. M. de la Cruz, and S. Esteban, "The control of specific actuators for fast ferry vertical motion damping," in Proceedings of the IEEE International Conference on Control Applications, Glasgow, Scotland, U.K. , 2002, pp. 304-309.

[22] S. Brizzolara, "Hydrodynamic analysis of interceptors with CFD methods," in Proceedings of The 7th International Conference on Fast Sea Transportation, Fast, 2003, p. 49.

[23] J. Giron-Sierra, S. Esteban, J. De la Cruz, B. De Andres, and J. Riola, "Fast ship's longitudinal motion attenuation with T-foil and flaps," in Novel Vehicle Concepts and Emerging Vehicle Technologies Symposium, Brussels, Belgium, 2003.

[24] S. Esteban, J. M. Giron-Sierra, B. de Andres-Toro, and J. M. De La Cruz, "Development of a control-oriented model of the vertical motions of a fast ferry," Journal of ship research, vol. 48, pp. 218-230, 2004.

[25] M. Davis, N. Watson, and D. Holloway, "Measurement of response amplitude operators for an 86 m high-speed catamaran," Journal of ship research, vol. 49, pp. 121-143, 2005.

[26] D. Holloway and M. Davis, "Ship motion computations using a high Froude number time domain strip theory," Journal of ship research, vol. 50, pp. 15-30, 2006.

[27] M. J. Hughes and K. M. Weems, "Time-domain seakeeping simulations for a high speed catamaran with an active ride control system," in Proceedings of the 11th International Conference on Fast Sea Transportation, Hawaii, USA, 2011.

[28] A. Rijkens, J. Keuning, and R. Huijsmans, "A computational tool for the design of ride control systems for fast planing vessels," International shipbuilding progress, vol. 58, pp. 165-190, 2011. 
[29] T. Shore, "Frequency response of motion controls on Incat catamaran model," BE Honours Thesis Honors Thesis, University of Tasmania, 2011.

[30] J. Bell, T. Arnold, J. Lavroff, and M. Davis, "Measured loading response of model motion control stern tabs," Royal Institution of Naval Architects. Transactions. Part A. International Journal of Maritime Engineering, vol. 155, pp. A1-A7, 2013.

[31] A. Rijkens, H. Cleijsen, and J. Keuning, "On the hydrodynamic performance of an improved motion control device for fast ships," in 12th International Conference on Fast Sea Transportation, Amsterdam, Netherlands, 2013.

[32] A. Haywood, B. Schaub, and C. Pappas, "Recent developments in ride control," in 13th International Conference on Fast Sea Transportation, Washington DC, USA, 2015.

[33] V. Hassani, S. A. Alterskjær, D. Fathi, O. Selvik, and L. O. Sæther, "Experimental results on motion regulation in high speed marine vessels," in Control and Automation (MED), 2014 22nd Mediterranean Conference of, 2014, pp. 487-492.

[34] J. Lavroff, M. R. Davis, D. S. Holloway, and G. Thomas, "The vibratory response of high-speed catamarans to slamming investigated by hydroelastic segmented model experiments," International Journal of Maritime Engineering, vol. 151, pp. 1-11, OctDec 2009.

[35] J. AlaviMehr, M. R. Davis, and J. Lavroff, "Low Reynolds Number Performance of a Model Scale T-Foil," Royal Institution of Naval Architects. Transactions. Part A3. International Journal of Maritime Engineering, vol. 157, pp. A175-A187, 2015.

[36] T. Arnold, J. Lavroff, and M. R. Davis, "Pressure distribution due to stern tab deflection at model scale," International Journal of Maritime Engineering, vol. 157, pp. 31-40, JanMar 2015.

[37] J. AlaviMehr, M. R. Davis, J. Lavroff, D. Holloway, and G. Thomas, "Response of a high-speed wave-piercing catamaran to an active ride control system," Royal Institution of Naval Architects. Transactions. Part A4. International Journal of Maritime Engineering, vol. 158, pp. A325-A336, 2016.

[38] J. Lavroff and M. R. Davis, "Slamming kinematics, impulse and energy transfer for wave-piercing catamarans," Journal of Ship Research, vol. 59, pp. 145-161, Sep 2015.

[39] J. Lavroff, M. R. Davis, D. S. Holloway, and G. Thomas, "Determination of wave slamming loads on high-speed catamarans by hydroelastic segmented model experiments," International Journal of Maritime Engineering, vol. 153, pp. A185-A197, Jul-Sep 2011.

[40] J. Lavroff, M. R. Davis, D. S. Holloway, and G. Thomas, "Wave slamming loads on wave-piercer catamarans operating at high-speed determined by hydro-elastic segmented model experiments," Marine Structures, vol. 33, pp. 120-142, Oct 2013.

[41] D. S. Holloway, J. Lavroff, and M. R. Davis, "Global structural design of hydroelastic models," in HIPER 06: 5th International Conference on High-performance Marine Vehicles, 2006, p. 253.

\section{Figures}




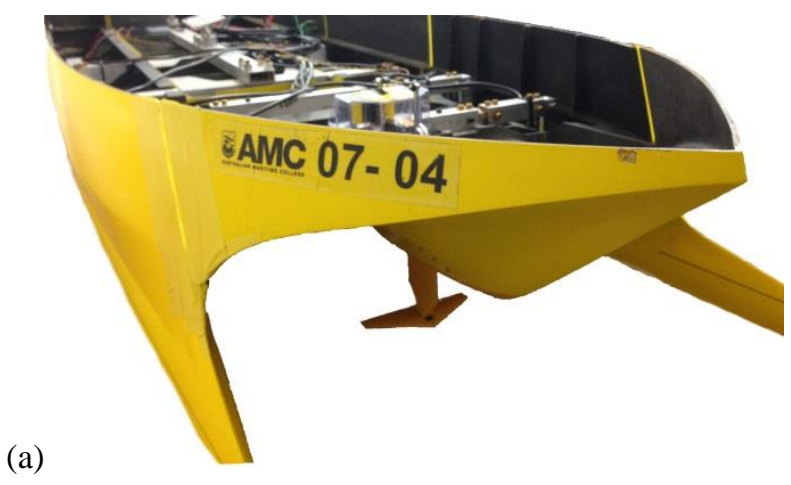

(b)

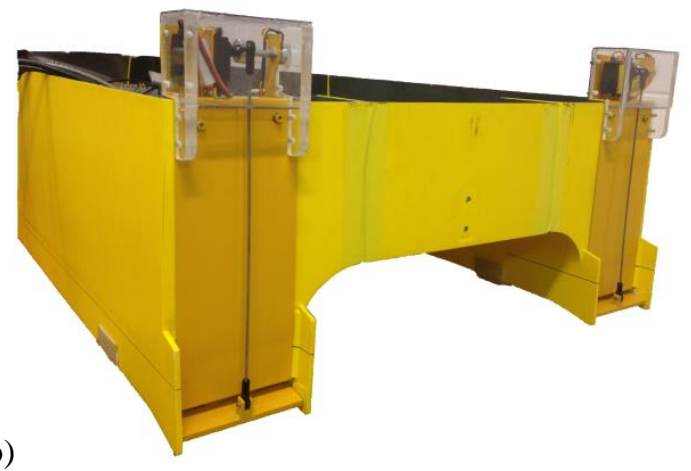

(c)

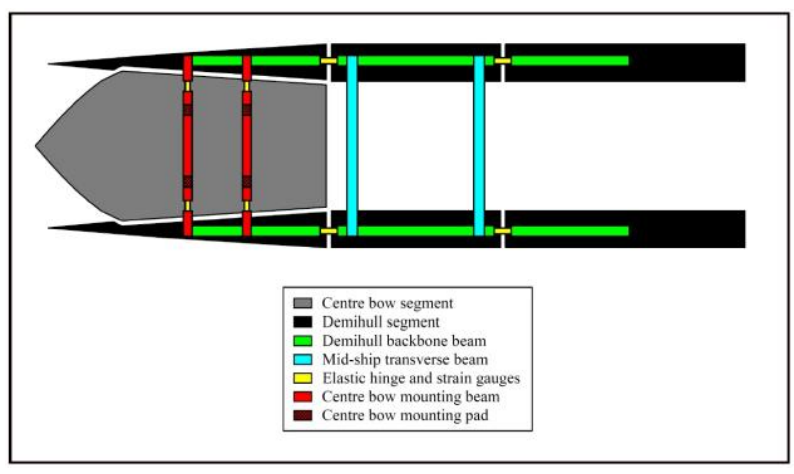

Figure 1: $2.5 \mathrm{~m}$ hydroelastic segmented catamaran model. (a) T-Foil installed on the aft section of the centre bow. (b) Stern tabs installed at the stern. (c) Schematic diagram (from Lavroff [34]) 
inming

II: $\sim m \sim m$ MMMMN

in:

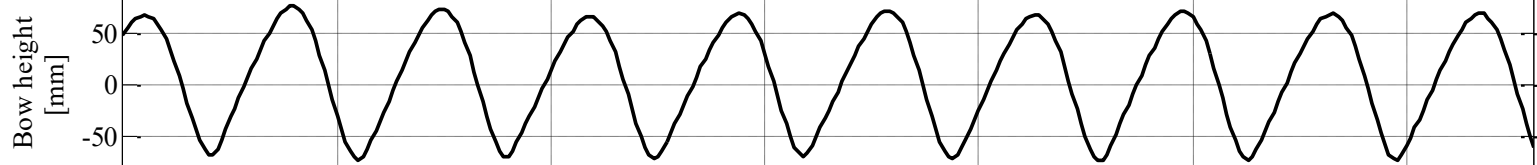

IDN $\sim \sim N$

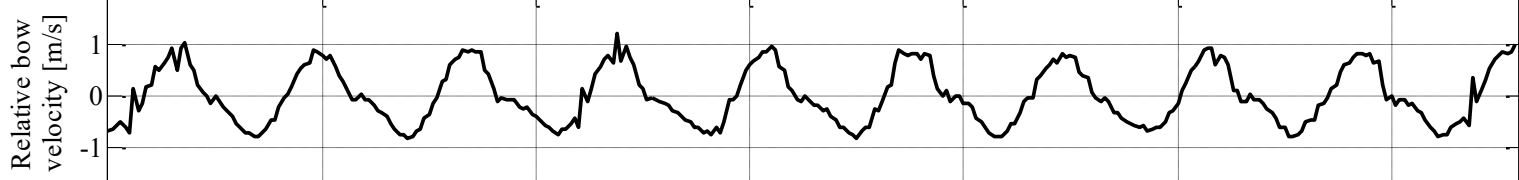

(100)

Figure 2: Typical time records of kinematic and slam load data at a model speed of $2.89 \mathrm{~m} / \mathrm{s}(\mathrm{Fr}=0.608)$, wave height of $90 \mathrm{~mm}$ and dimensionless wave encounter frequency $\omega_{e}^{*}=4.581$ using the RCS in pitch control mode. 


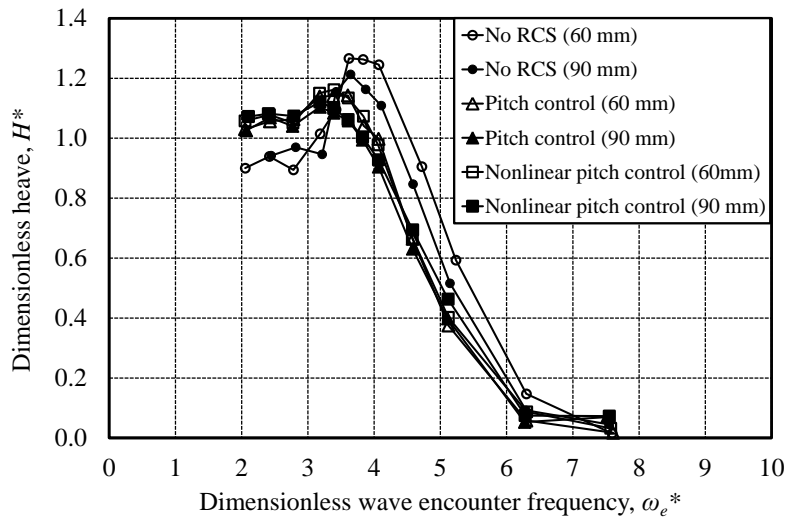

(a)

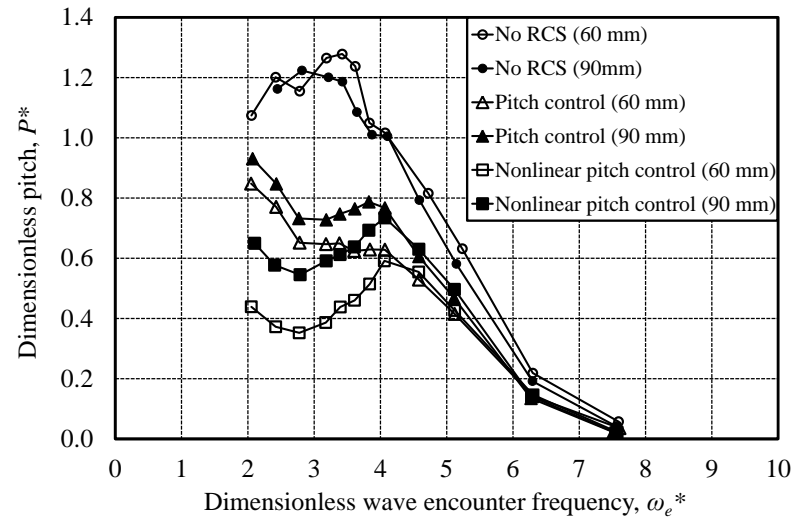

(b)

Figure 3: Motion response to head waves with linear and nonlinear RCS pitch feedback algorithm. Model speed $2.89 \mathrm{~m} / \mathrm{s}(\mathrm{Fr}=0.608)$ (wave height is shown in the legend) (a) Heave RAO. (b) Pitch RAO.

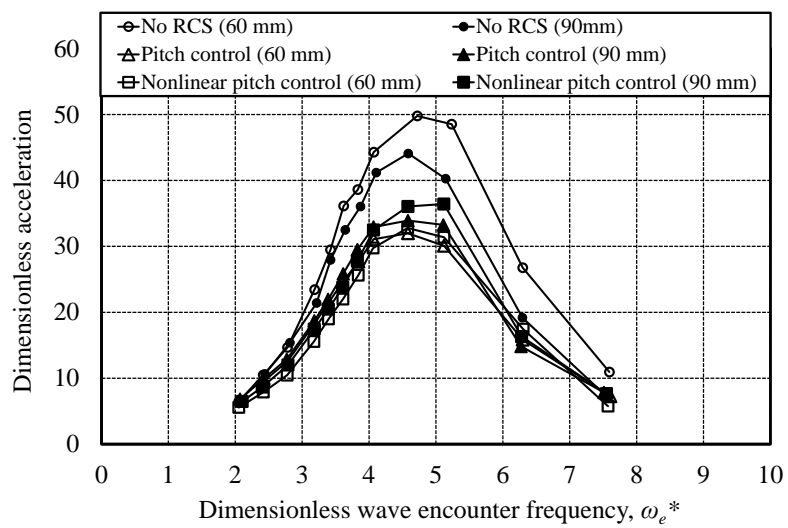

Figure 4: Dimensionless heave acceleration $\left(H^{*} \omega_{e}^{* 2}\right)$ where $H^{*}$ is the local vertical motion amplitude/wave amplitude at the longitudinal location of the T-Foil (80\% LOA from the stern) at a model speed of $2.89 \mathrm{~m} / \mathrm{s}(\mathrm{Fr}=$ $0.608)$.

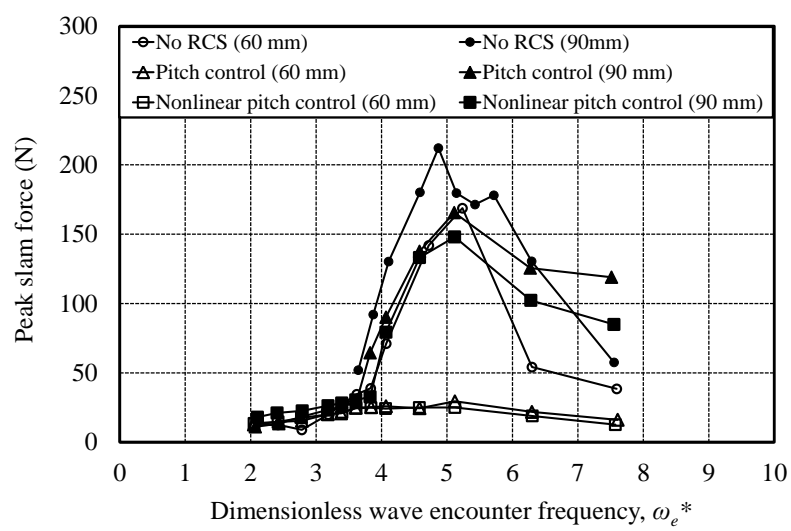

Figure 5: Centre bow peak slam force (N, model scale) at model speed of $2.89 \mathrm{~m} / \mathrm{s}(\mathrm{Fr}=0.608)$. 


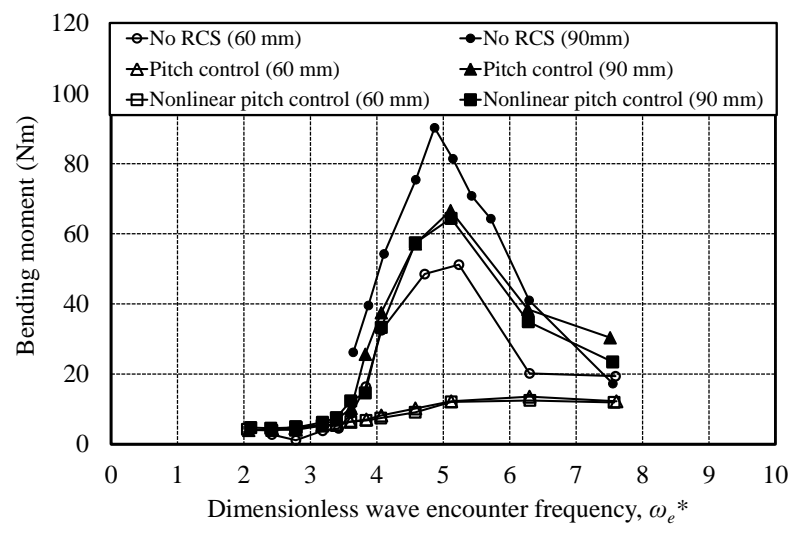

Figure 6: Demi-hull peak slam induced sagging bending moment $(\mathrm{Nm})$ at the forward segment link position at model speed of $2.89 \mathrm{~m} / \mathrm{s}(\mathrm{Fr}=0.608)$. 


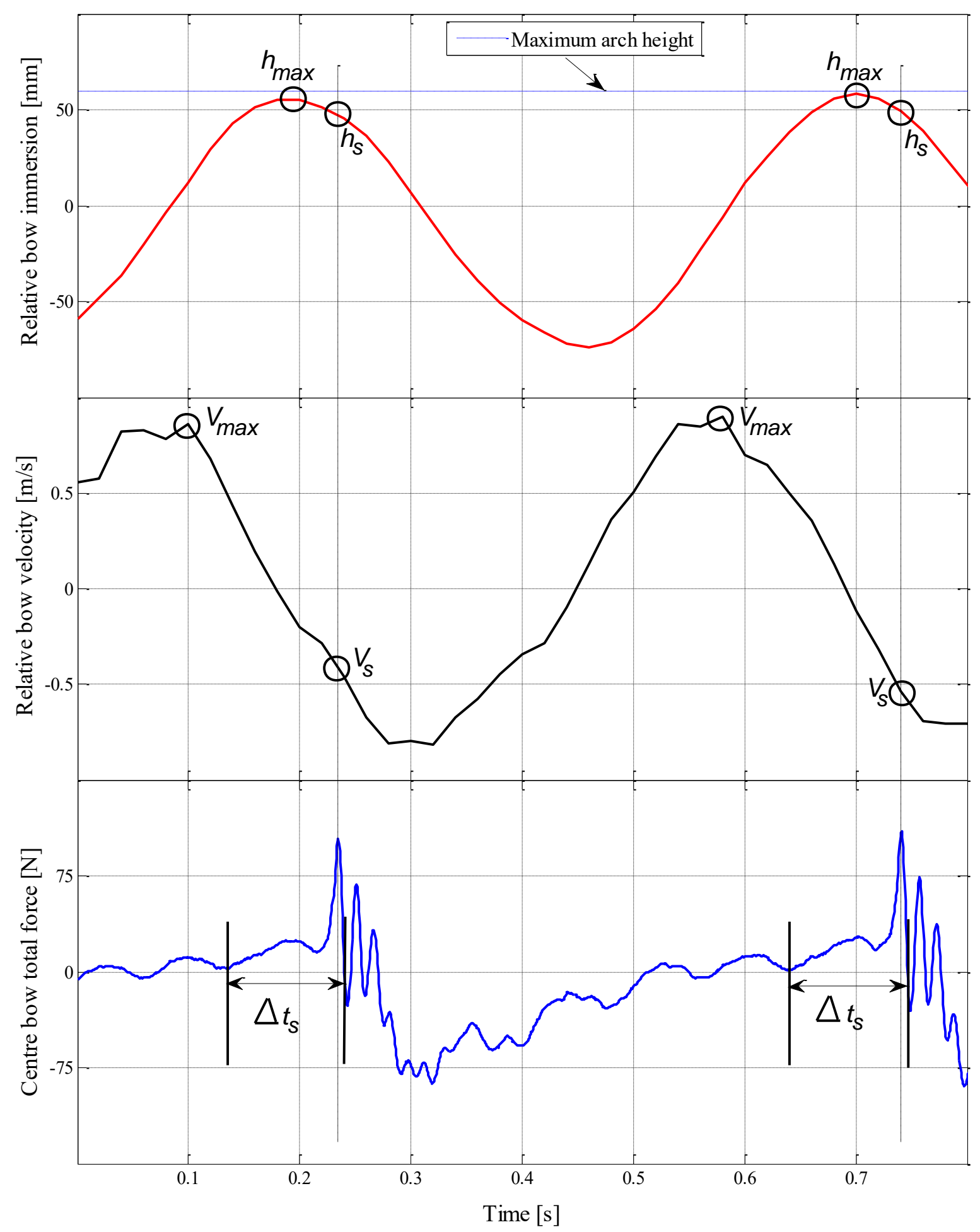

Figure 7: Designation of key kinematic parameters using data obtained at a model speed of $2.89 \mathrm{~m} / \mathrm{s}(\mathrm{Fr}=0.608)$, wave height of $90 \mathrm{~mm}$ and dimensionless wave encounter frequency $\omega_{e}^{*}=6.272 \mathrm{using}$ the RCS in pitch control mode. 


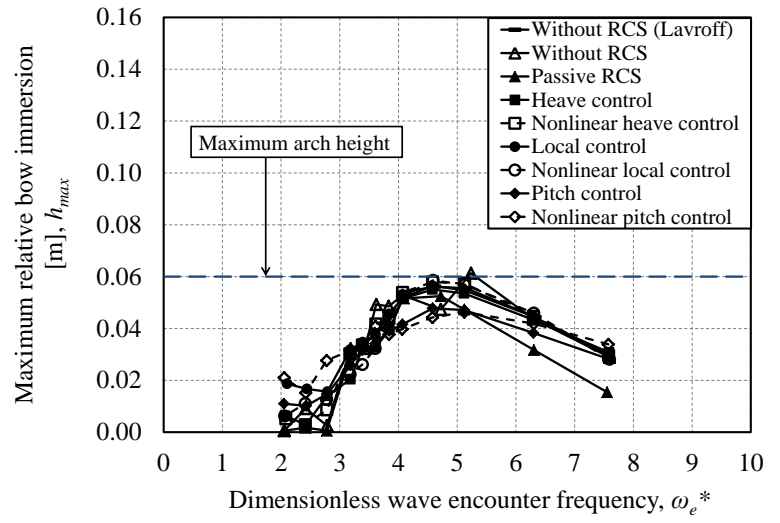

(a)

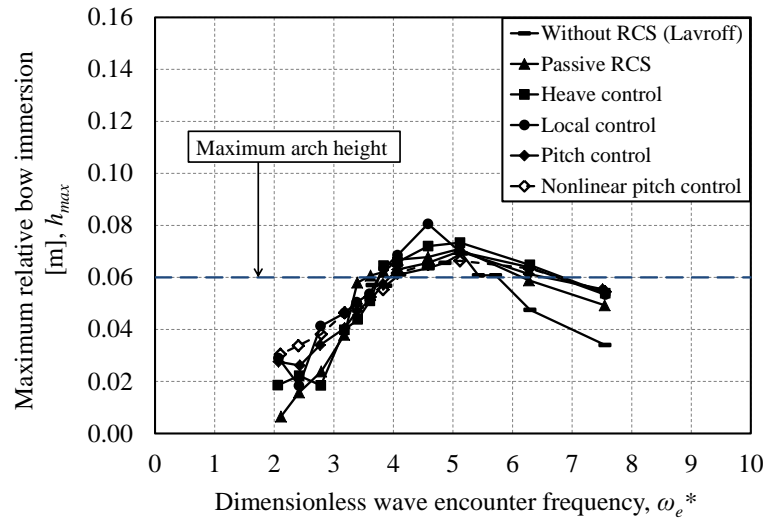

(b)

Figure 8: Maximum relative bow immersion, $h_{\max }$, at a model speed of $2.89 \mathrm{~m} / \mathrm{s}(\mathrm{Fr}=0.608)$ : (a) Wave height of 60 $\mathrm{mm}$. (b) Wave height of $90 \mathrm{~mm}$.

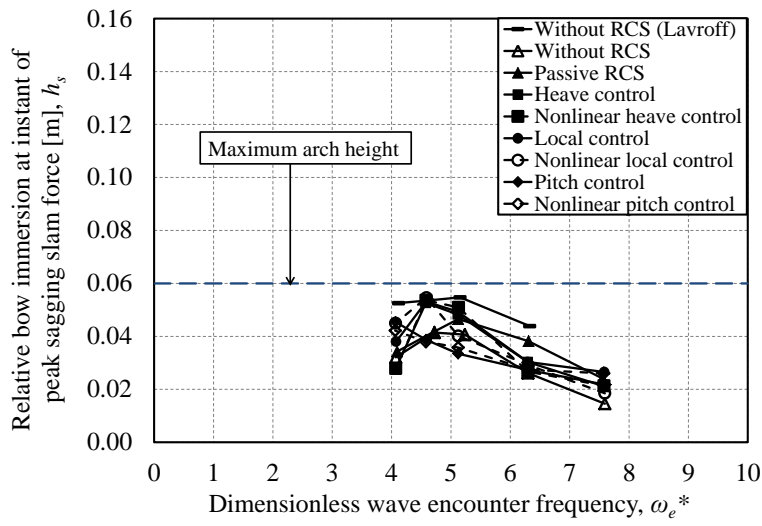

(a)

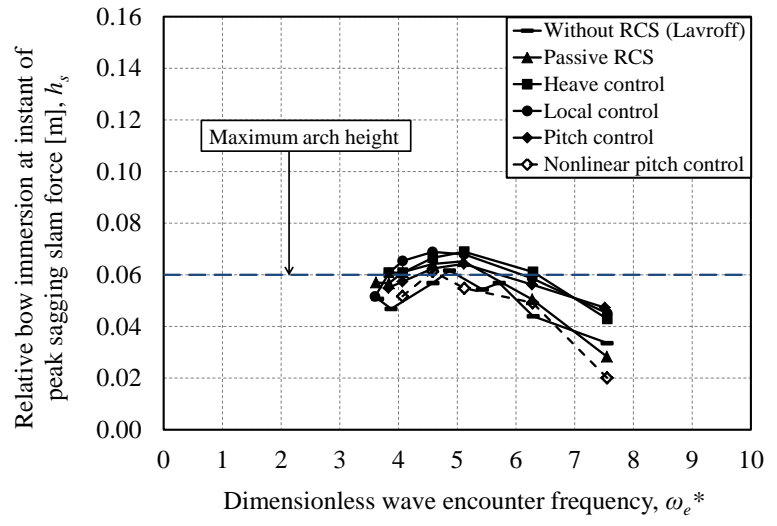

(b)

Figure 9: Relative bow immersion at the instant of peak sagging slam force, $h_{s}$, at a model speed of $2.89 \mathrm{~m} / \mathrm{s}(\mathrm{Fr}=$ 0.608): (a) Wave height of $60 \mathrm{~mm}$. (b) Wave height of $90 \mathrm{~mm}$.

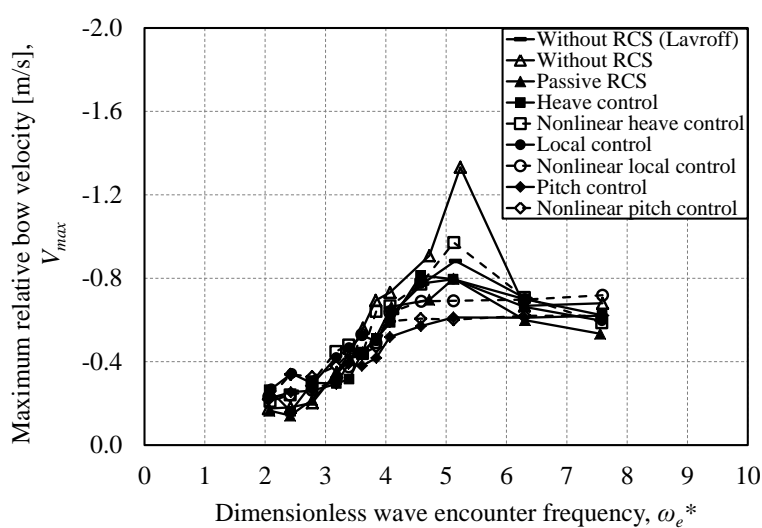

(a)

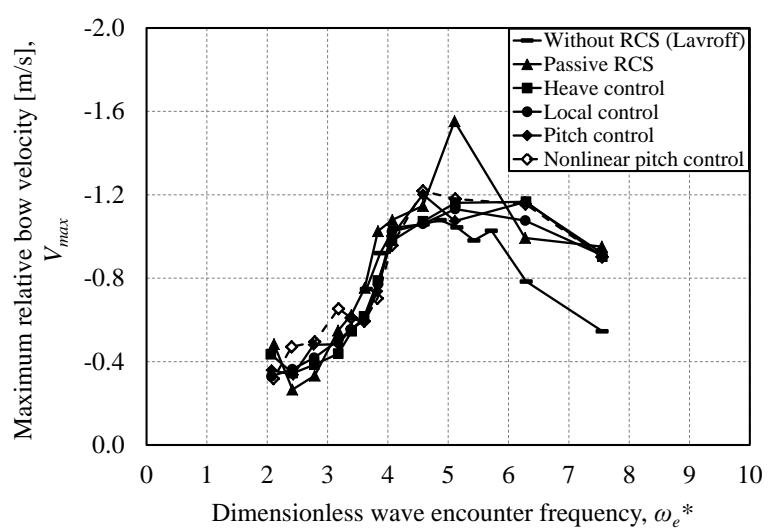

(b)

Figure 10: Maximum relative bow vertical velocity, $V_{\max }$, at a model speed of $2.89 \mathrm{~m} / \mathrm{s}(\mathrm{Fr}=0.608)$ : (a) Wave height of $60 \mathrm{~mm}$. (b) Wave height of $90 \mathrm{~mm}$. 


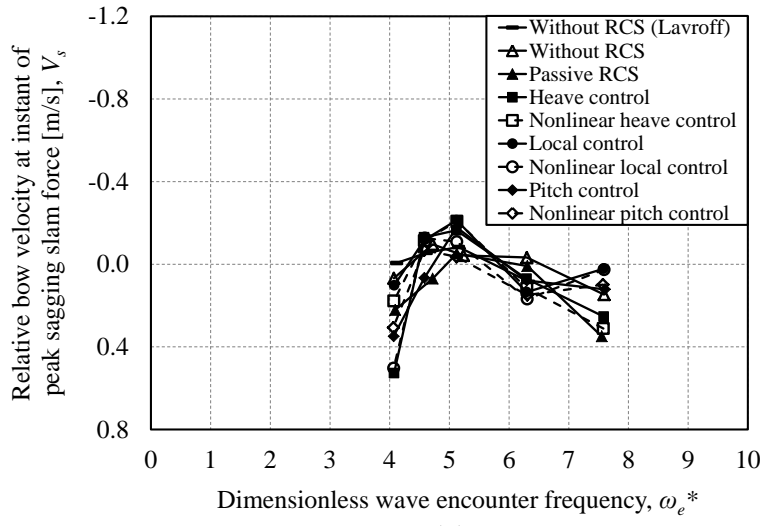

(a)

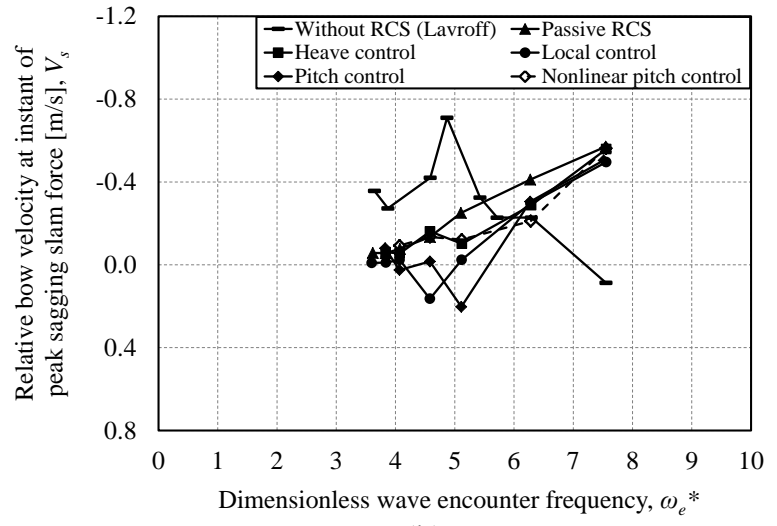

(b)

Figure 11: Relative bow vertical velocity at the instant of sagging slam force, $V_{s}$, at a model speed of $2.89 \mathrm{~m} / \mathrm{s}(\mathrm{Fr}$ =0.608): (a) Wave height of $60 \mathrm{~mm}$. (b) Wave height of $90 \mathrm{~mm}$.

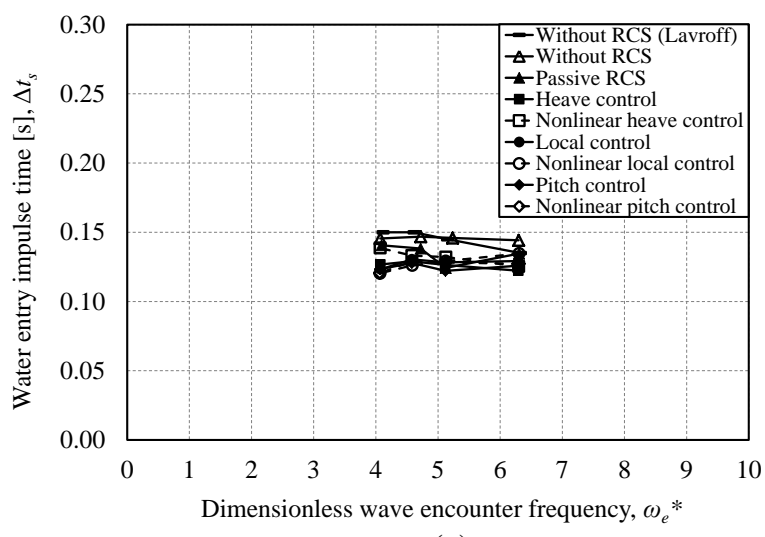

(a)

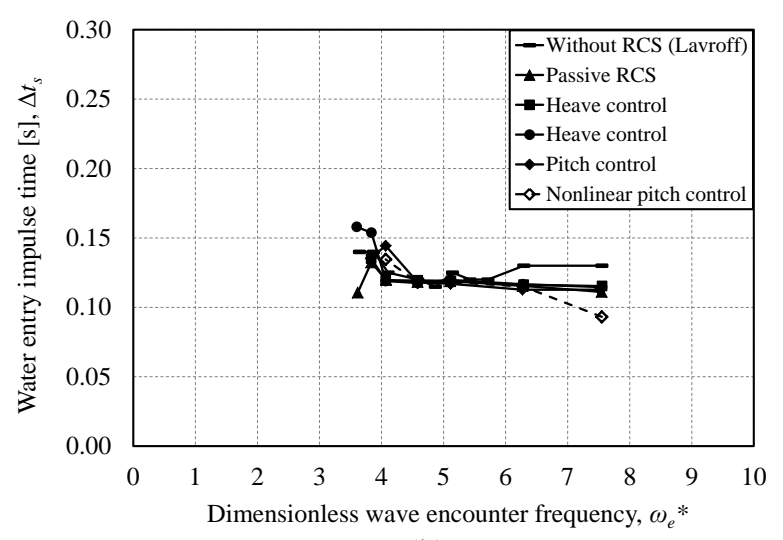

(b)

Figure 12: Water entry impulse integration time at a model speed of $2.89 \mathrm{~m} / \mathrm{s}(\mathrm{Fr}=0.608)$ : (a) Wave height of 60 $\mathrm{mm}$. (b) Wave height of $90 \mathrm{~mm}$.

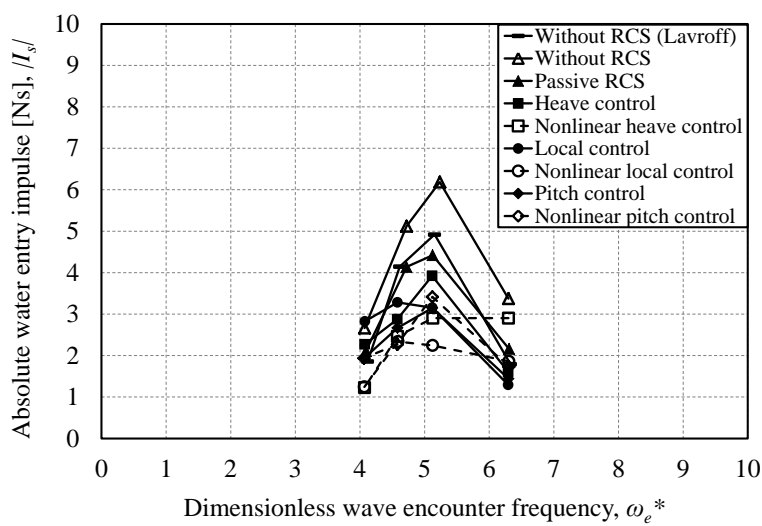

(a)

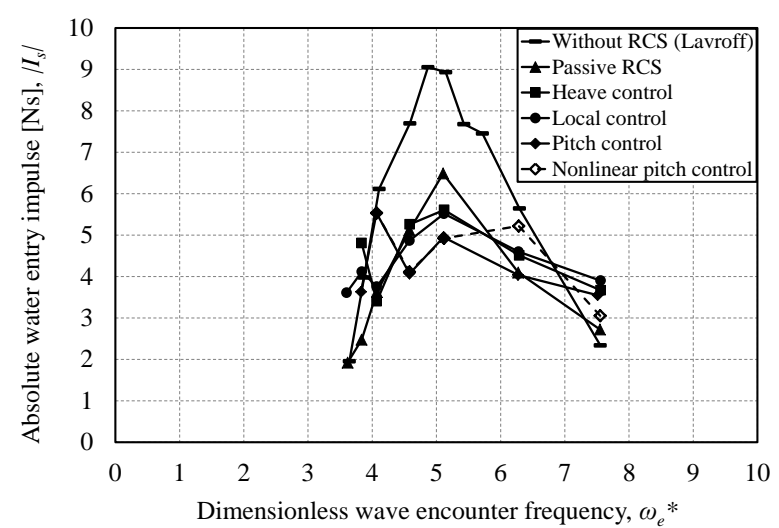

(b)

Figure 13: Absolute water entry impulse at a model speed of $2.89 \mathrm{~m} / \mathrm{s}(\mathrm{Fr}=0.608)$ : (a) Wave height of $60 \mathrm{~mm}$. (b) Wave height of $90 \mathrm{~mm}$. 


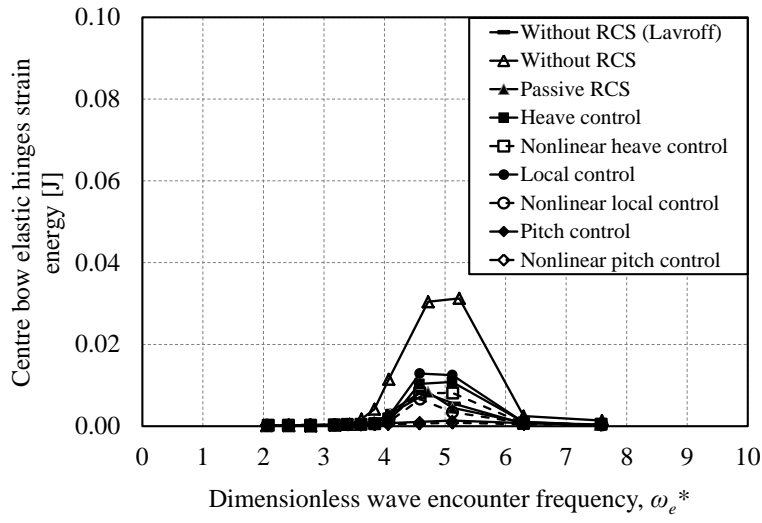

(a)

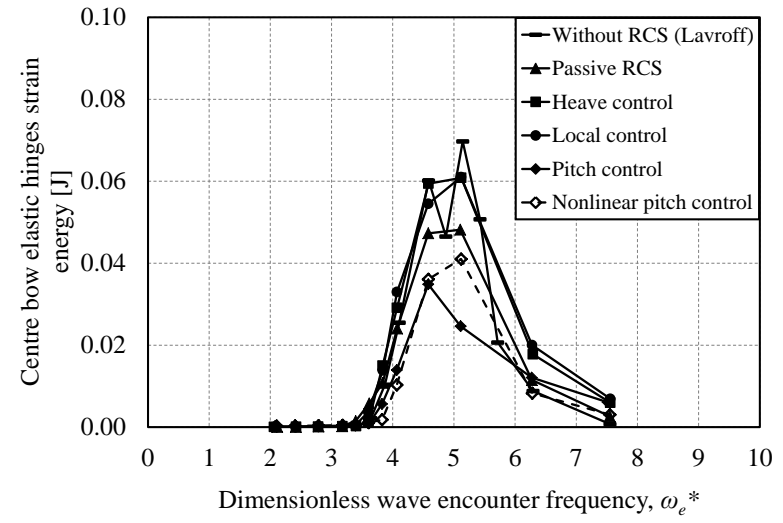

(b)

Figure 14: Peak strain energy of the centre bow elastic links at a model speed of $2.89 \mathrm{~m} / \mathrm{s}(\mathrm{Fr}=0.608)$ : (a) Wave height of $60 \mathrm{~mm}$. (b) Wave height of $90 \mathrm{~mm}$.

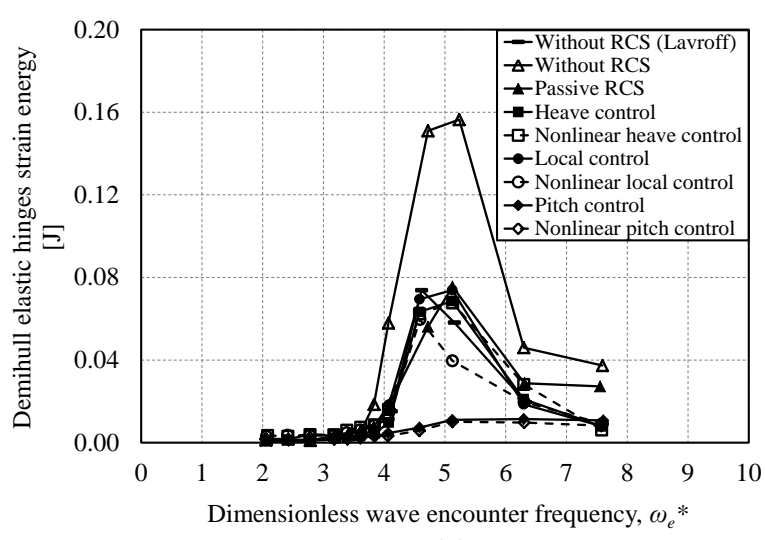

(a)

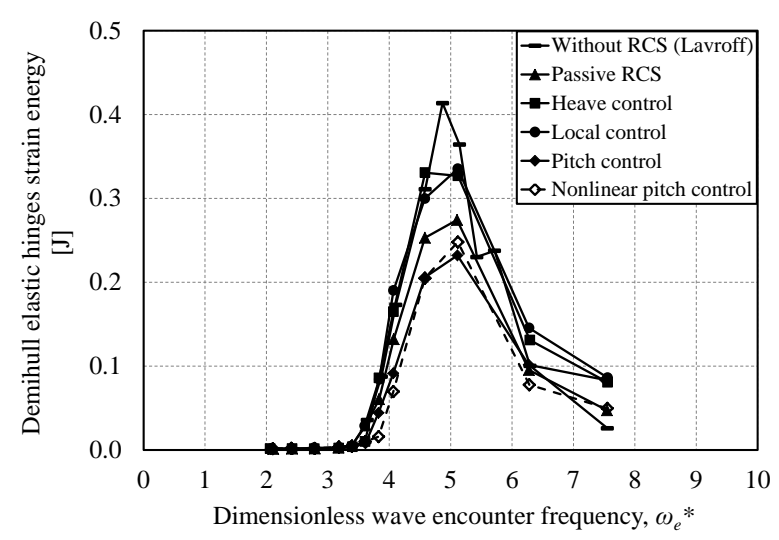

(b)

Figure 15: Peak strain energy of the demi-hull elastic links at a model speed of $2.89 \mathrm{~m} / \mathrm{s}(\mathrm{Fr}=0.608)$ : (a) Wave height of $60 \mathrm{~mm}$. (b) Wave height of $90 \mathrm{~mm}$.

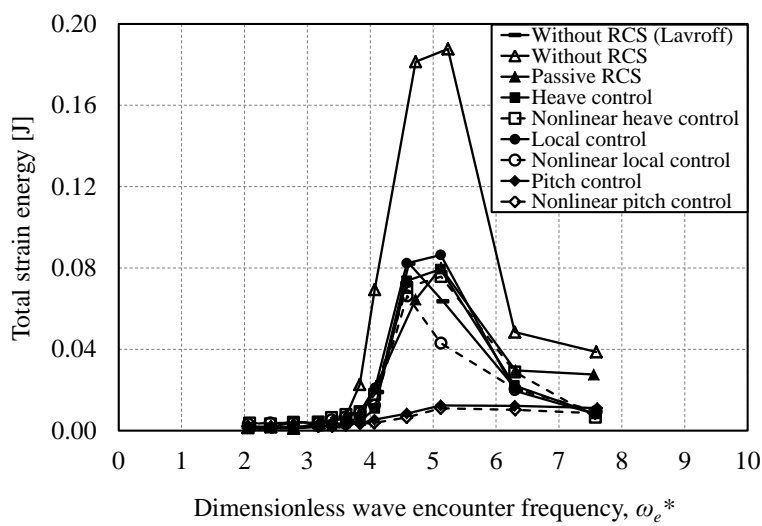

(a)

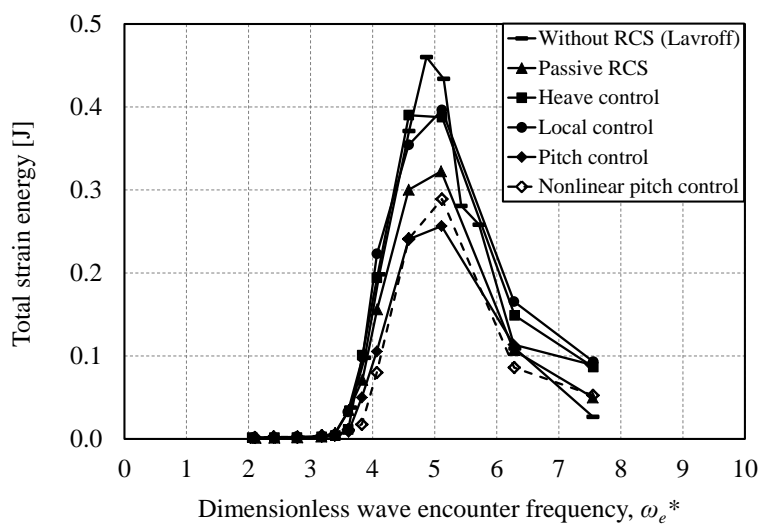

(b)

Figure 16: Total peak strain energy of the centre bow and demi-hull elastic links at a model speed of $2.89 \mathrm{~m} / \mathrm{s}(\mathrm{Fr}=$ 0.608): (a) Wave height of $60 \mathrm{~mm}$. (b) Wave height of $90 \mathrm{~mm}$. 